\title{
Relações estruturais e de diversidade de uma floresta ripária em unidade de conservação e sua zona de amortecimento
}

\section{Structural and diversity relationships of a riparian forest in a conservation unit and its buffer zone}

\author{
Kelly Marianne Guimarães Pereira ${ }^{1}$, Natielle Gomes Cordeiro ${ }^{2}$, Lucas Deziderio Santana ${ }^{3}$, Inkamauta Valeda Cerda Plazas ${ }^{4}$, \\ Lisandra Maria Alves Matos ${ }^{5}$, Christian Dias Cabacinha ${ }^{6}$
}

Resumo: O objetivo do estudo foi analisar a estrutura, diversidade e heterogeneidade do componente arbóreo de uma Mata Ripária em uma Unidade de Conservação. Além disso, comparar a estrutura desta vegetação com a Mata Ripária da zona de amortecimento. A área de estudo está situada no Parque Estadual Lapa Grande, Minas Gerias (Brasil). O inventário florestal foi realizado na unidade de conservação (UC) e na sua zona de amortecimento. Como critério de inclusão, mensurou-se todos os indivíduos com DAP $\geq 3 \mathrm{~cm}$, bem como a sua altura total. Processou-se os parâmetros fitossociológicos e florísticos da vegetação, e empreendeu-se a análise de correspondência distendida (DCA), análise de agrupamento de "cluster" do coeficiente de similaridade de Horn e o coeficiente de Jaccard. Foram amostrados 1.426 indivíduos dentro da unidade de conservação e 944 indivíduos para a zona de amortecimento. O índice de diversidade de Shannon encontrado para a UC foi de 4,61 nats.ind ${ }^{-1}$, a equabilidade de Pielou de 0,85. Em relação a zona de amortecimento, os valores de diversidade foram de 3,79 nats.ind ${ }^{-1}$, equabilidade de 0,82 . Foi observado uma diferença significativa entre as diversidades das duas áreas, com valores de $\mathrm{t}=10,98$ para $\mathrm{p}<0,001$. Ao realizar a similaridade das parcelas através da análise de Cluster observa-se que as parcelas não formaram grupos distintos, a DCA mostrou a formação de fortes gradientes florísticos entre os ambientes. Conclui-se que há uma heterogeneidade entre as áreas. Além disso, as áreas da unidade de conservação e sua zona de amortecimento desempenham um papel de importância para conservação.

Palavras-chave: Cerrado; Fitossociologia; Heterogeneidade.

Abstract: The aim of the study was to analyze the structure, diversity and heterogeneity of the arboreal component of a Riparian Forest in a Conservation Unit. In addition, to compare the structure of this vegetation with the Mata Ripária of the buffer zone. The study area is located in the Lapa Grande State Park, Minas Gerais State (Brazil). The forest inventory was carried out in the conservation unit and in its buffer zone. As a criterion, all individuals with a DBH $\geq 3 \mathrm{~cm}$ were measured, as well as their total height. The phytosociological and floristic parameters of the vegetation were processed, and the extendedcorrespondence analysis (DCA), cluster analysis of the Horn's similarity and the Jaccard coefficient were performed. We sampled 1,426 individuals in the interior and 944 individuals in the buffer zone. The diversity index of Shannon reached to the conservation unit was 4.61 nats.ind $^{-1}$, the Pielou equability of 0.85 . In relation to the buffer zone, the values of diversity were 3.79 nats.ind $^{-1}$, equability of 0.82 . A significant difference was observed between the diversities of the two areas, with values of $\mathrm{t}=10.98$ for $\mathrm{p}<0.001$. When realizing the similarity of the plots through Cluster analysis it is observed that the plots did not formed distinctives groups, the DCA showed the formation of strong floristic gradients between the environments. We conclude that there is a heterogeneity between the areas. In addition, the areas of the conservation unit and its buffer zone play a major role for conservation.

Key words: Cerrado; Phytosociology; Heterogeneity.

\footnotetext{
*Autor para correspondência

Recebido para publicação em 09/08/2018; aprovado em 17/09/2018

${ }^{1}$ Eng. Florestal, Mestranda do programa de Engenharia Florestal, Universidade Federal de Lavras, Lavras, (38) 99145-0315, kellyguimaraes10@ gmail.com.

${ }^{2}$ Eng. Florestal, Mestranda do programa de Engenharia Florestal, Universidade Federal de Lavras, Lavras, (38) 98828-7450, natiellegcordeiro@ gmail.com. ${ }^{3}$ Biólogo, Doutorando do programa de Engenharia Florestal, Universidade Federal de Lavras, Lavras, (32) 99163-9327, lucasdeziderio01@gmail.com. ${ }^{4}$ Graduando em Engenharia Florestal, Universidade Estadual do Sudoeste da Bahia, Vitória da Conquista, (77) 98878-1416, inkamauta@ @otmail.com.

${ }^{5}$ Eng. Florestal, Mestranda do programa de Engenharia Florestal, Universidade Federal do Paraná, Curitiba, (38) 99169-9497, lisandraamatos@ gmail.com.

${ }^{6}$ Eng. Florestal, Dr. Professor Adjunto do curso de Engenharia Florestal, Universidade Federal de Minas Gerais, Montes Claros, (38) 99806-4301, christian.cabacinha@gmail.com
} 


\section{INTRODUÇÃO}

O Cerrado é considerado como hotspot ou área prioritária de conservação mundial devido à biodiversidade que abriga, além de significativo número de espécies endêmicas. $\mathrm{O}$ domínio se destaca por propiciar um ambiente adequado para a manutenção dos ecossistemas e fornece habitat para uma flora rica em espécies com usos múltiplos, sendo empregadas como subsídio de sobrevivência para a população local (SILVA et al., 2008; SIMON et al., 2009; STRASSBURG et al., 2017).

Ocupando uma área de aproximadamente dois milhões de hectares, distribuídos em diversos estados do país, o Cerrado é o segundo maior domínio do Brasil, perdendo apenas para a Floresta Amazônica (SANO et al., 2010). No entanto, o domínio vem sofrendo com perdas no habitat devido à utilização de forma inadequada de seus recursos naturais, além do uso para atividades produtivas como agropecuária e pastagem, bem como a intensa urbanização (CHAVES, 2016; TOLLEFSON, 2018).

O Cerrado, formado por um mosaico de fitofisionomias que abrangem desde campos abertos até florestas densas, tem como fisionomia mais representativa o cerrado sensu stricto, com árvores e arbustos tortuosos, de baixo porte e casca grossa (MORENO et al., 2015; FINGER; FINGER, 2015). As formações do domínio são influenciadas por fatores como clima, solo e relevo e se destacam por abordar uma diversidade geomorfológica e possuir uma extensa variação latitudinal (GARÇÃO; SOUZA, 2017; MORETTO, 2016).

A fitofisionomia Mata Ripária, também conhecida como mata ciliar ou mata de galeria, é caracterizada por ser uma vegetação com importância significativa na conservação ecológica e hidrológica, principalmente por estabelecer a interação entre esses fatores (CASTRO et al., 2013). A mata ciliar se caracteriza por ser propícia à diferentes níveis de deciduidade no período de seca e a não ocorrência do encontro do dossel, distinguindo-se assim das matas de galeria que se designam pelo aspecto perenifólio (RIBEIRO; WALTER, 1998).

Assim como as demais fitofisionomias do Cerrado, as matas ripárias sofrem com a degradação em consequência das atividades antrópicas. Contudo, a existência dessa vegetação favorece a redução de efeitos negativos aos cursos d'água como a sedimentação (OLIVEIRA et al., 2011), pois exercem diversas funções, destacando seu importante papel no fluxo gênico, vegetal e animal (BRANCALION et al., 2016), o que permite inferir sobre sua irrefutável importância e necessidade do conhecimento da sua estrutura, bem como a mitigação de estratégias que visem sua conservação (COSTA et al., 2013). Além disso, características intrínsecas, como tolerância a inundações periódicas e adaptação em áreas com alto grau de declividade, são atribuídas às matas ripárias (SALAMENE et al., 2011)

A conservação e recuperação dos ecossistemas têm sido objetivo de muitos estudos devido à constante utilização dos recursos naturais, por vezes sem a devida atenção e cuidado, o que ocasiona situações ambientais indesejadas como mudança climática, extinção da fauna e flora (TILMAN et al., 2017). Atentando-se a este fator, é decisivo a existências de áreas protegidas que possibilitem o fomento da biodiversidade e recursos naturais.
As unidades de conservação, consideradas como áreas protegidas, visam assegurar a manutenção das condições ecológicas e propiciar a perpetuação das espécies vegetais e animais, isto é, são áreas estabelecidas objetivando conservar os remanescentes florestais e sua biodiversidade. A minimização destes impactos é propiciada pelas áreas delimitadas no entorno, ou seja, áreas circundantes à região de proteção definidas como zona de amortecimento (COSTA et al., 2013), que estão intimamente relacionadas com o isolamento das espécies nativas presentes na unidade de conservação, servindo como corredor ecológico para a fauna e flora (NORA; SANTOS, 2011; NASCIMENTO; DOMINGUEZ, 2010).

O conhecimento da composição e estrutura da floresta permite inferir sobre a potencialidade da vegetação, fornecendo informações quanto à conservação e preservação dos recursos naturais (KUNZ et al., 2014). A instauração do Parque Estadual Lapa Grande, que possui importância significativa para a região na qual está inserido, tem como objetivo a conservação e proteção dos recursos disponíveis. $\mathrm{O}$ parque abriga uma expressiva diversidade em fauna e flora, além de considerável número de grutas e mananciais que abastecem em $30 \%$ de água a cidade próxima (MINAS GERAIS, 2006).

Tendo em vista o cenário, o presente estudo objetivou analisar a estrutura, diversidade e heterogeneidade do componente arbóreo de uma Mata Ripária em área de Cerrado em uma Unidade de Conservação no norte de Minas Gerais (Brasil). Além disso, comparar a estrutura desta vegetação arbórea com a Mata Ripária da zona de amortecimento da Unidade de Conservação.

\section{MATERIAL E MÉTODOS}

A área de estudo é caracterizada por uma vegetação de Mata Ripária do domínio Cerrado, situada no Parque Estadual Lapa Grande, no município de Montes Claros - MG, sob as coordenadas $16^{\circ} 42^{\prime} 8.76^{\prime \prime S}$ e $43^{\circ} 54^{\prime} 57.98^{\prime \prime} \mathrm{W}$. A unidade de conservação (UC) está enquadrada pelo o Sistema Nacional de Unidades de Conservação como de Proteção Integral. O clima predominante da região corresponde ao tipo Aw segundo a classificação de Köppen e Geiger, caracterizado por uma pluviosidade média anual de 1.086,4 $\mathrm{mm}$, temperatura média anual de $23,10{ }^{\circ} \mathrm{C}$ e altitude variando entre 680 e 1.028 m (ALVARES et al., 2013).

O inventário florestal foi realizado nos anos de 2014 e 2015 na unidade de conservação e na sua zona de amortecimento, sendo esta demarcada a partir um raio de 10 km no entorno da Unidade de Conservação. Realizou-se uma amostragem aleatória de parcelas de área fixa com a alocação de 24 unidades amostrais no interior e 12 na zona de amortecimento, com dimensões de $20 \mathrm{~m}$ x $20 \mathrm{~m}\left(400 \mathrm{~m}^{2}\right)$, totalizando 0,96 ha e 0,48 ha amostrados, respectivamente. Como critério de inclusão, mensurou-se todos os indivíduos lenhosos arbóreos com diâmetro a 1,30 metro do solo (DAP) $\geq 3 \mathrm{~cm}$ por meio do uso de fita métrica, bem como a sua altura total em metros, com a utilização de vara telescópica. Os indivíduos que atenderam o critério de inclusão foram marcados com placas de alumínio constando um número para sua identificação (MORO; MARTINS, 2011).

Procedeu-se a identificação taxonômica no campo e para as espécies não identificadas coletou-se o material botânico 
para posterior identificação a partir de consultas em herbários, literaturas específicas e consulta à especialistas (SILVAJÚNIOR; PEREIRA, 2012). As espécies foram confirmadas quanto ao seu nome científico na lista de espécies da flora do Brasil e as famílias foram classificadas de acordo com o sistema do Angiosperm Phylogeny Group IV (APG IV, 2016; FLORA DO BRASIL, 2018).

Foram obtidos os parâmetros fitossociológicos e florísticos da vegetação, que são: índice de diversidade de Shannon, equabilidade de Pielou, número de indivíduos, densidade absoluta e relativa, dominância absoluta e relativa, frequência absoluta e relativa e índice de valor de importância. Assim também foram calculadas a estrutura diamétrica, pelo método estatístico, com a utilização do desvio padrão dos diâmetros, sendo distribuídas em 10 classes, considerando uma amplitude de $8 \mathrm{~cm}$. Ademais, a estrutura hipsométrica foi estabelecida pela estratificação da comunidade em três estratos: inferior, médio e superior (BROWER et al., 1997; MUELLER-DOMBOIS; ELLENBERG, 1974).

Empreendeu-se a análise de correspondência distendida (DCA) e a análise de agrupamento de "cluster" do coeficiente de similaridade de Horn para dados quantitativos e o coeficiente de Jaccard para dados qualitativos, permitindo a interpretação da heterogeneidade entre o interior e a zona de amortecimento da UC. Esses coeficientes exibem um intervalo de 0 a 1 e a significância é atribuída para os dados quantitativos quando forem > 0,5 (FELFILI et al., 2011) e os dados qualitativos quando forem $>0,25$ (MUELLERDOMBOIS; ELLENBERG, 1974). A fim de verificar a existência de diferença estatística entre as diversidades de espécies (H') utilizou-se o Teste t com nível de significância de $\mathrm{p}<0,001$. Ambas as análises foram realizadas no software Past (HAMMER et al., 2001).

\section{RESULTADOS E DISCUSSÃO}

No inventário florestal foram amostrados 1.426 indivíduos (1.485 ind.ha ${ }^{-1}$ ), que abrangem 144 espécies, 122 gêneros, distribuídos em 47 famílias para o interior e 944 indivíduos (1.967 ind.haํ) que correspondem a 71 espécies e 62 gêneros, classificados em 29 famílias para a zona de amortecimento. O diâmetro e altura média foram respectivamente de $8,75 \mathrm{~cm}$ e $6,91 \mathrm{~m}$ para o interior e 7,99 $\mathrm{cm}$ e 5,16 m para a zona de amortecimento.
As famílias mais ricas, que somam $60 \%$ do total de espécies, foram Fabaceae (38 spp.), Myrtaceae (20 spp.), Malvaceae e Sapindaceae (8 spp.), Anacardiaceae, Apocynaceae, Meliaceae e Salicaceae (7 spp.), Combretaceae e Rubiaceae (6 spp.) para o interior. Em relação à zona de amortecimento destacam-se as famílias Fabaceae (17 spp.), Myrtaceae (12 spp.), Anacardiaceae (5 spp.), Malpighiaceae (4 spp), Apocynaceae, Meliaceae, Moraceae, Rubiaceae e Sapindaceae (3 spp.) e Bignoniaceae (2 spp.), que somam $70 \%$ das espécies. Essas famílias são encontradas comumente em outros estudos em áreas de Mata Ripária, principalmente a família Fabaceae, sendo a mais frequente nos levantamentos (CERQUEIRA et al., 2016; MINAMI et al., 2017; SILVA NETO et al., 2016). Essa família tem uma ampla distribuição, devido à sua grande quantidade de espécies e gêneros, sendo que está entre as maiores famílias das Angiospermas (FLORES; RODRIGUES, 2010). Além disso, está presente em quase todos os domínios e possui alta capacidade de fixação de nitrogênio, que confere às espécies um melhor desempenho, quanto à colonização e recuperação de ecossistemas (MALCZEWSKI et al., 2014; SOUZA, 2010). Do mesmo modo, a família Myrtaceae apresentou um grande número de espécies para as duas áreas, o que confirma a sua importância de acordo com o estudo realizado em Mata de Galeria em Goiás, onde foi a família relatada com maior número de indivíduos (OLIVEIRA et al., 2015).

Para toda a comunidade foi encontrada que as dez espécies com maiores índices de valor de importância (IVI), representam aproximadamente $30 \%$ de todas as espécies para cada levantamento. Destaca-se as espécies Myracrodruon urundeuva Allemão, Guazuma ulmifolia Lam., Copaifera langsdorffii Desf. e Myrciaria floribunda (H.West ex Willd.) O. Berg que são comuns entre as duas áreas e estão presentes na lista das mais representativas com maiores IVI. As espécies mais relevantes possuem ampla distribuição no Brasil, o que explica sua incidência em ambas as áreas (FLORA DO BRASIL, 2018). Além disso, a espécie $M$. urundeuva também foi encontrada com a mais importante em estudo similar em Minas Gerais (CARVALHO et al., 2005). Pode-se também justificar a presença da $M$. floribunda pela sua associação com cursos d'água e ambientes úmidos (NUNES et al., 2009; PEREIRA, 2015) (Tabela 1).

Tabela 1. Fitossociologia das áreas de Mata Ripária da Unidade de Conservação, em ordem crescente de IVI do interior . Em que: N: Número de indivíduos; Dab: Densidade absoluta; Dre = densidade relativa $(\%)$; Fab: Frequência absoluta; Fre = frequência relativa (\%); DoA: Dominância absoluta; DoR = dominância relativa (\%); IVI = índice de valor de importância.

\begin{tabular}{|c|c|c|c|c|c|c|c|c|c|c|c|c|c|c|c|c|}
\hline \multirow{2}{*}{ Nome Científico } & \multicolumn{8}{|c|}{ Mata Ripária Interior } & \multicolumn{8}{|c|}{ Mata Ripária Entorno } \\
\hline & $\mathbf{N}$ & Dab & Dre & Fab & Fre & DoA & DoR & IVI & $\mathbf{N}$ & Dab & Dre & Fab & Fre & DoA & DoR & IVI \\
\hline Myracrodruon urundeuva Allemão & 115 & 115 & 8,06 & 58,33 & 3,00 & 1,33 & 8,82 & 19,88 & 122 & 244 & 12,92 & 83,33 & 4,12 & 2,48 & 15,81 & 32,85 \\
\hline Guazuma ulmifolia Lam. & 95 & 95 & 6,66 & 54,17 & 2,78 & 0,92 & 6,14 & 15,58 & 56 & 112 & 5,93 & 58,33 & 2,88 & 1,05 & 6,68 & 15,49 \\
\hline Aspidosperma sp. & 43 & 43 & 3,02 & 29,17 & 1,50 & 1,31 & 8,71 & 13,23 & 1 & 2 & 0,11 & 8,33 & 0,41 & 0,01 & 0,05 & 0,57 \\
\hline $\begin{array}{l}\text { Anadenanthera colubrina (Vell.) } \\
\text { Brenan }\end{array}$ & 38 & 38 & 2,66 & 29,17 & 1,50 & 1,16 & 7,70 & 11,86 & 11 & 22 & 1,17 & 25,00 & 1,23 & 0,49 & 3,11 & 5,51 \\
\hline Copaifera langsdorffii Desf. & 34 & 34 & 2,38 & 37,50 & 1,93 & 0,42 & 2,79 & 7,11 & 30 & 60 & 3,18 & 33,33 & 1,65 & 0,61 & 3,89 & 8,72 \\
\hline Cordiera sessilis (Vell.) Kuntze & 60 & 60 & 4,21 & 20,83 & 1,07 & 0,16 & 1,09 & 6,37 & 34 & 68 & 3,60 & 41,67 & 2,06 & 0,19 & 1,22 & 6,88 \\
\hline $\begin{array}{l}\text { Myrciaria floribunda (H.West ex } \\
\text { Willd.) O.Berg }\end{array}$ & 41 & 41 & 2,88 & 16,67 & 0,86 & 0,29 & 1,94 & 5,67 & 33 & 66 & 3,50 & 33,33 & 1,65 & 0,85 & 5,43 & 10,57 \\
\hline Terminalia argentea Mart. & 12 & 12 & 0,84 & 29,17 & 1,50 & 0,49 & 3,24 & 5,59 & - & - & - & - & - & - & - & - \\
\hline Syzygium jambos (L.) Alston & 9 & 9 & 0,63 & 12,50 & 0,64 & 0,58 & 3,87 & 5,15 & - & - & - & - & - & - & - & - \\
\hline $\begin{array}{l}\text { Deguelia costata (Benth.) } \\
\text { A.M.G.Azevedo \& R.A.Camargo }\end{array}$ & 14 & 14 & 0,98 & 16,67 & 0,86 & 0,43 & 2,86 & 4,69 & - & - & - & - & - & - & - & - \\
\hline
\end{tabular}


Alibertia edulis (Rich.) A.Rich. Cariniana estrellensis (Raddi) Kuntze

Cupania vernalis Cambess.

Xylopia frutescens Aubl.

Cordiera macrophylla (K.Schum.)

Kuntze

Dipteryx alata Vogel

Enterolobium gummiferum (Mart.) J.F.Macbr.

Bowdichia virgilioides Kunth Dilodendron bipinnatum Radlk.

Guarea guidonia (L.) Sleumer

Cedrela fissilis Vell.

Inga cinnamomea Spruce ex Benth.

Lithraea molleoides (Vell.) Engl.

Inga sp.

Indeterminada 1

Annona sp.

Luehea grandiflora Mart. \& Zucc.

Tabebuia roseoalba (Ridl.)

Sandwith

Tapirira guianensis Aubl.

Prumus sp.

Machaerium hirtum (Vell.)

Stellfeld

Terminalia glabrescens Mart.

Myrcia guianensis (Aubl.) DC.

Cecropia glaziovii Snethl.

Indeterminada 2

Swartzia langsdorffii Raddi

Himatanthus obovatus (Müll. Arg.)

Woodson

Myrcia splendens (Sw.) DC.

Astronium fraxinifolium Schott

Piper sp.

Bauhinia forficata Link

Ziziphus joazeiro Mart.

Guarea macrophylla Vahl

Ocotea spixiana (Nees) Mez

Annona sylvatica A.St.-Hil.

Plinia cauliflora (Mart.) Kausel

Indeterminada 3

Senna multijuga (Rich.) H.S.Irwin \& Barneby

Trichilia hirta L.

Eremanthus erythropappus (DC.)

MacLeish

Terminalia reitzii Exell

Cecropia pachystachya Trécul

Hymenaea stigonocarpa Mart. ex

Hayne

Trichilia sp.

Qualea grandiflora Mart.

Handroanthus ochraceus (Cham.)

Mattos

Guapira graciliflora (Mart. ex

Schmidt) Lundell

Aegiphila verticillata Vell.

Combretum leprosum Mart.

Indeterminada 4

Eugenia sp.

Magonia pubescens A.St.-Hil. $\begin{array}{llllllll}33 & 33 & 2,31 & 29,17 & 1,50 & 0,13 & 0,86 & 4,67\end{array}$

$\begin{array}{llllllll}3 & 3 & 0,21 & 4,17 & 0,21 & 0,55 & 3,68 & 4,10\end{array}$

$\begin{array}{llllllllllllllll}17 & 17 & 1,19 & 33,33 & 1,71 & 0,11 & 0,76 & 3,66 & 10 & 20 & 1,06 & 8,33 & 0,41 & 0,15 & 0,93 & 2,40\end{array}$

$\begin{array}{llllllllllllllll}23 & 23 & 1,61 & 12,50 & 0,64 & 0,17 & 1,15 & 3,41 & 1 & 2 & 0,11 & 8,33 & 0,41 & 0,00 & 0,01 & 0,53\end{array}$

$\begin{array}{llllllll}35 & 35 & 2,45 & 8,33 & 0,43 & 0,07 & 0,47 & 3,35\end{array}$

$\begin{array}{llllllll}5 & 5 & 0,35 & 8,33 & 0,43 & 0,36 & 2,42 & 3,20\end{array}$

$\begin{array}{llllllll}8 & 8 & 0,56 & 25,00 & 1,28 & 0,20 & 1,30 & 3,14\end{array}$

$\begin{array}{llllllll}25 & 25 & 1,75 & 16,67 & 0,86 & 0,07 & 0,45 & 3,06\end{array}$

$\begin{array}{lllllllll}16 & 16 & 1,12 & 20,83 & 1,07 & 0,12 & 0,81 & 3,00\end{array}$

$\begin{array}{lllllllll}14 & 14 & 0,98 & 12,50 & 0,64 & 0,20 & 1,31 & 2,93\end{array}$

$\begin{array}{llllllll}5 & 5 & 0,35 & 16,67 & 0,86 & 0,24 & 1,57 & 2,78\end{array}$

$\begin{array}{lllllllll}15 & 15 & 1,05 & 4,17 & 0,21 & 0,21 & 1,41 & 2,67\end{array}$

$\begin{array}{lllllllll}11 & 11 & 0,77 & 25,00 & 1,28 & 0,07 & 0,47 & 2,53\end{array}$

$\begin{array}{llllllll}12 & 12 & 0,84 & 20,83 & 1,07 & 0,09 & 0,60 & 2,51\end{array}$

$\begin{array}{llllllll}20 & 20 & 1,40 & 4,17 & 0,21 & 0,11 & 0,72 & 2,34\end{array}$

$\begin{array}{llllllll}19 & 19 & 1,33 & 12,50 & 0,64 & 0,05 & 0,35 & 2,32\end{array}$

$\begin{array}{llllllll}4 & 4 & 0,28 & 8,33 & 0,43 & 0,24 & 1,57 & 2,28\end{array}$

$\begin{array}{llllllll}7 & 7 & 0,49 & 16,67 & 0,86 & 0,14 & 0,92 & 2,27\end{array}$

$\begin{array}{llllllll}12 & 12 & 0,84 & 8,33 & 0,43 & 0,14 & 0,93 & 2,20\end{array}$

$\begin{array}{llllllll}4 & 4 & 0,28 & 12,50 & 0,64 & 0,18 & 1,22 & 2,15\end{array}$

$\begin{array}{llllllll}9 & 9 & 0,63 & 25,00 & 1,28 & 0,03 & 0,22 & 2,13\end{array}$

$18 \quad 0,95 \quad 41,67 \quad 2,06 \quad 0,30 \quad 1,91 \quad 4,92$

$\begin{array}{llllllll}5 & 5 & 0,35 & 8,33 & 0,43 & 0,20 & 1,32 & 2,10\end{array}$

$\begin{array}{lllllllll}13 & 13 & 0,91 & 16,67 & 0,86 & 0,05 & 0,33 & 2,10\end{array}$

$\begin{array}{llllllll}8 & 8 & 0,56 & 12,50 & 0,64 & 0,13 & 0,88 & 2,09\end{array}$

$\begin{array}{lllllllll}13 & 13 & 0,91 & 4,17 & 0,21 & 0,14 & 0,93 & 2,05\end{array}$

$\begin{array}{llllllll}11 & 11 & 0,77 & 16,67 & 0,86 & 0,06 & 0,40 & 2,03\end{array}$

$\begin{array}{llllllll}15 & 15 & 1,05 & 12,50 & 0,64 & 0,05 & 0,33 & 2,02\end{array}$

$\begin{array}{llllllll}11 & 11 & 0,77 & 16,67 & 0,86 & 0,05 & 0,35 & 1,98\end{array}$

$\begin{array}{llllllll}9 & 9 & 0,63 & 16,67 & 0,86 & 0,06 & 0,42 & 1,91\end{array}$

$\begin{array}{lllllllll}8 & 8 & 0,56 & 25,00 & 1,28 & 0,01 & 0,06 & 1,91\end{array}$

$\begin{array}{llllllll}10 & 10 & 0,70 & 20,83 & 1,07 & 0,01 & 0,08 & 1,85\end{array}$

$\begin{array}{llllllll}6 & 6 & 0,42 & 25,00 & 1,28 & 0,02 & 0,12 & 1,83\end{array}$

$\begin{array}{llllllll}4 & 4 & 0,28 & 12,50 & 0,64 & 0,14 & 0,91 & 1,83\end{array}$

$\begin{array}{llllllll}13 & 13 & 0,91 & 4,17 & 0,21 & 0,09 & 0,58 & 1,71\end{array}$

$\begin{array}{llllllll}8 & 8 & 0,56 & 16,67 & 0,86 & 0,04 & 0,28 & 1,70\end{array}$

$\begin{array}{lllllllll}12 & 12 & 0,84 & 12,50 & 0,64 & 0,03 & 0,19 & 1,68\end{array}$

$\begin{array}{llllllll}6 & 6 & 0,42 & 12,50 & 0,64 & 0,09 & 0,59 & 1,66\end{array}$

$\begin{array}{llllllll}8 & 8 & 0,56 & 16,67 & 0,86 & 0,03 & 0,22 & 1,64\end{array}$

$\begin{array}{llllllll}9 & 9 & 0,63 & 16,67 & 0,86 & 0,02 & 0,10 & 1,59\end{array}$

$\begin{array}{llllllll}9 & 9 & 0,63 & 12,50 & 0,64 & 0,05 & 0,31 & 1,58\end{array}$

$\begin{array}{llllllll}9 & 9 & 0,63 & 4,17 & 0,21 & 0,10 & 0,69 & 1,54\end{array}$

$\begin{array}{llllllll}9 & 9 & 0,63 & 8,33 & 0,43 & 0,07 & 0,43 & 1,49\end{array}$

$\begin{array}{llllllll}5 & 5 & 0,35 & 12,50 & 0,64 & 0,07 & 0,49 & 1,48\end{array}$

$\begin{array}{llllllll}4 & 4 & 0,28 & 12,50 & 0,64 & 0,08 & 0,54 & 1,46\end{array}$

$\begin{array}{lllllllll}10 & 10 & 0,70 & 4,17 & 0,21 & 0,08 & 0,51 & 1,43\end{array}$

$\begin{array}{llllllll}5 & 5 & 0,35 & 16,67 & 0,86 & 0,03 & 0,22 & 1,43\end{array}$

$\begin{array}{llllllll}7 & 7 & 0,49 & 12,50 & 0,64 & 0,04 & 0,25 & 1,38\end{array}$

$\begin{array}{llllllllllllllll}8 & 8 & 0,56 & 12,50 & 0,64 & 0,03 & 0,18 & 1,38 & 8 & 16 & 0,85 & 41,67 & 2,06 & 0,10 & 0,62 & 3,53\end{array}$

$\begin{array}{llllllll}6 & 6 & 0,42 & 16,67 & 0,86 & 0,01 & 0,08 & 1,36\end{array}$

$\begin{array}{llllllll}12 & 12 & 0,84 & 4,17 & 0,21 & 0,04 & 0,30 & 1,35\end{array}$

$\begin{array}{llllllllllllll}0,42 & 8,33 & 0,43 & 0,07 & 0,50 & 1,35 & 4 & 8 & 0,42 & 16,7 & 0,82 & 0,02 & 0,11 & 1,36\end{array}$

$\begin{array}{llllllllllllllll}13 & 13 & 0,91 & 4,17 & 0,21 & 0,02 & 0,14 & 1,27 & 9 & 18 & 0,95 & 8,33 & 0,41 & 0,09 & 0,56 & 1,93\end{array}$ 
Aloysia virgata (Ruiz \& Pav.) Juss.

Hymenolobium sp.

Allophylus racemosus Sw.

Aspidosperma pyrifolium Mart.

Celtis sp.

Swartzia sp.

Pouteria gardneri (Mart. \& Miq.)

Baehni

Indeterminada 5

Indeterminada 6

Maprounea guianensis Aubl.

Acrocomia aculeata (Jacq.) Lodd. ex Mart.

Byrsonima verbascifolia (L.) DC.

Croton urucurana Baill.

Roupala montana Aubl.

Maprounea brasiliensis A.St.-Hil.

Inga vera Willd.

Casearia rupestris Eichler

Platymiscium floribundum Vogel

Albizia niopoides (Spruce ex

Benth.) Burkart

Lecythis pisonis Cambess.

Schinopsis brasiliensis Engl.

Indeterminada 7

Indeterminada 8

Indeterminada 9

Protium sp.

Maclura tinctoria (L.) D.Don ex

Steud.

Guarea kunthiana A.Juss.

Indeterminada 10

Kielmeyera sp.

Qualea dichotoma (Mart.) Warm.

Casearia sylvestris $\mathrm{Sw}$.

Erytrina sp.

Indeterminada 11

Aspidosperma subincanum Mart.

Vochysia tucanorum Mart.

Indeterminada 12

Ficus gomelleira Kunth

Tachigali aurea Tul.

Chrysophyllum marginatum (Hook.

\& Arn.) Radlk.

Xylosma venosa N.E.Br.

Dimorphandra macrostachya

Benth.

Mangifera indica L.

Indeterminada 13

Zanthoxylum rhoifolium Lam.

Nectandra sp.

Dimorphandra gardneriana Tul.

Indeterminada 14

Indeterminada 15

Cheirochinum sp.

Brosimum gaudichaudii Trécul

Indeterminada 16

Indeterminada 17

Myrcia tomentosa (Aubl.) DC.

Psidium sp.

Chrysophyllum marginatum (Hook. \& Arn.) Radlk.

Heliocarpus popayanensis Kunth $\begin{array}{llllll}0,28 & 16,67 & 0,86 & 0,02 & 0,12 & 1,26\end{array}$

$\begin{array}{lllllll}0,56 & 8,33 & 0,43 & 0,04 & 0,26 & 1,25\end{array}$

$\begin{array}{lllllll}0,42 & 12,50 & 0,64 & 0,03 & 0,18 & 1,24\end{array}$

$\begin{array}{lllllll}0,35 & 12,50 & 0,64 & 0,04 & 0,24 & 1,24\end{array}$

$\begin{array}{lllllll}0,49 & 12,50 & 0,64 & 0,01 & 0,08 & 1,21\end{array}$

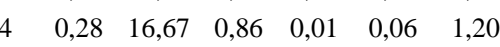

$\begin{array}{llllllll}6 & 6 & 0,42 & 12,50 & 0,64 & 0,02 & 0,12 & 1,18\end{array}$

$\begin{array}{llllllll}2 & 2 & 0,14 & 4,17 & 0,21 & 0,12 & 0,79 & 1,14\end{array}$

$\begin{array}{llllllll}6 & 6 & 0,42 & 4,17 & 0,21 & 0,07 & 0,48 & 1,12\end{array}$

$\begin{array}{llllllll}5 & 5 & 0,35 & 12,50 & 0,64 & 0,02 & 0,12 & 1,11\end{array}$

$\begin{array}{llllllll}1 & 1 & 0,07 & 4,17 & 0,21 & 0,12 & 0,81 & 1,10\end{array}$

$\begin{array}{llllllll}7 & 7 & 0,49 & 8,33 & 0,43 & 0,03 & 0,17 & 1,09\end{array}$

$\begin{array}{lllllllll}3 & 3 & 0,21 & 12,50 & 0,64 & 0,04 & 0,23 & 1,09\end{array}$

$\begin{array}{llllllll}4 & 4 & 0,28 & 12,50 & 0,64 & 0,02 & 0,16 & 1,08\end{array}$

$\begin{array}{lllllll}5 & 0,35 & 12,50 & 0,64 & 0,01 & 0,08 & 1,07\end{array}$

$\begin{array}{llllllll}5 & 0,35 & 8,33 & 0,43 & 0,04 & 0,28 & 1,06\end{array}$

$\begin{array}{llllllll}4 & 4 & 0,28 & 12,50 & 0,64 & 0,02 & 0,11 & 1,03\end{array}$

$\begin{array}{llllllll}3 & 3 & 0,21 & 12,50 & 0,64 & 0,03 & 0,17 & 1,03\end{array}$

$\begin{array}{llllllll}7 & 7 & 0,49 & 8,33 & 0,43 & 0,02 & 0,11 & 1,03\end{array}$

$\begin{array}{llllllll}5 & 5 & 0,35 & 8,33 & 0,43 & 0,03 & 0,22 & 1,00\end{array}$

$\begin{array}{llllllll}5 & 5 & 0,35 & 8,33 & 0,43 & 0,03 & 0,21 & 0,99\end{array}$

$\begin{array}{llllllll}7 & 7 & 0,49 & 4,17 & 0,21 & 0,04 & 0,28 & 0,99\end{array}$

$\begin{array}{lllllllll}3 & 3 & 0,21 & 8,33 & 0,43 & 0,05 & 0,34 & 0,98\end{array}$

$\begin{array}{lllllllll}2 & 2 & 0,14 & 4,17 & 0,21 & 0,09 & 0,63 & 0,98\end{array}$

$\begin{array}{llllllll}4 & 4 & 0,28 & 8,33 & 0,43 & 0,04 & 0,27 & 0,98\end{array}$

$\begin{array}{llllllll}4 & 4 & 0,28 & 12,50 & 0,64 & 0,01 & 0,05 & 0,97\end{array}$

$\begin{array}{lllllll}2 & 0,14 & 4,17 & 0,21 & 0,09 & 0,61 & 0,96\end{array}$

$\begin{array}{llllllll}2 & 2 & 0,14 & 8,33 & 0,43 & 0,05 & 0,36 & 0,93\end{array}$

$\begin{array}{lllllll}7 & 0,49 & 4,17 & 0,21 & 0,03 & 0,21 & 0,91\end{array}$

$\begin{array}{llllllll}5 & 0,35 & 8,33 & 0,43 & 0,02 & 0,13 & 0,91\end{array}$

$\begin{array}{llllllll}8 & 8 & 0,56 & 4,17 & 0,21 & 0,02 & 0,12 & 0,90\end{array}$

$\begin{array}{llllllll}1 & 1 & 0,07 & 4,17 & 0,21 & 0,09 & 0,61 & 0,89\end{array}$

$\begin{array}{llllllll}6 & 6 & 0,42 & 4,17 & 0,21 & 0,04 & 0,26 & 0,89\end{array}$

$\begin{array}{llllllll}3 & 3 & 0,21 & 12,50 & 0,64 & 0,01 & 0,04 & 0,89\end{array}$

$\begin{array}{lllllllll}3 & 3 & 0,21 & 8,33 & 0,43 & 0,03 & 0,22 & 0,86\end{array}$

$\begin{array}{lllllllll}5 & 5 & 0,35 & 4,17 & 0,21 & 0,04 & 0,28 & 0,84\end{array}$

$\begin{array}{llllllll}4 & 4 & 0,28 & 8,33 & 0,43 & 0,02 & 0,13 & 0,84\end{array}$

$\begin{array}{llllllll}6 & 6 & 0,42 & 4,17 & 0,21 & 0,03 & 0,18 & 0,81\end{array}$

$4 \quad 4 \quad \begin{array}{lllllll}4,28 & 8,33 & 0,43 & 0,01 & 0,10 & 0,81\end{array}$

$\begin{array}{llllllll}6 & 6 & 0,42 & 4,17 & 0,21 & 0,02 & 0,16 & 0,80\end{array}$

$\begin{array}{llllllll}3 & 3 & 0,21 & 8,33 & 0,43 & 0,02 & 0,13 & 0,77\end{array}$

$\begin{array}{llllllll}1 & 1 & 0,07 & 4,17 & 0,21 & 0,07 & 0,47 & 0,76\end{array}$

$\begin{array}{llllllll}4 & 4 & 0,28 & 8,33 & 0,43 & 0,01 & 0,04 & 0,75\end{array}$

$\begin{array}{llllllll}3 & 3 & 0,21 & 8,33 & 0,43 & 0,01 & 0,09 & 0,73\end{array}$

$\begin{array}{lllllllll}3 & 3 & 0,21 & 8,33 & 0,43 & 0,01 & 0,09 & 0,72\end{array}$

$\begin{array}{llllllll}2 & 2 & 0,14 & 4,17 & 0,21 & 0,06 & 0,37 & 0,72\end{array}$

$\begin{array}{llllllll}3 & 3 & 0,21 & 8,33 & 0,43 & 0,01 & 0,08 & 0,72\end{array}$

$\begin{array}{llllllll}2 & 2 & 0,14 & 4,17 & 0,21 & 0,05 & 0,35 & 0,70\end{array}$

$\begin{array}{lllllllll}3 & 3 & 0,21 & 8,33 & 0,43 & 0,01 & 0,06 & 0,70\end{array}$

$\begin{array}{llllllll}2 & 2 & 0,14 & 8,33 & 0,43 & 0,02 & 0,13 & 0,70\end{array}$

$\begin{array}{llllllll}5 & 5 & 0,35 & 4,17 & 0,21 & 0,02 & 0,13 & 0,70\end{array}$

$\begin{array}{llllllll}3 & 3 & 0,21 & 4,17 & 0,21 & 0,04 & 0,27 & 0,69\end{array}$

$\begin{array}{llllllll}3 & 3 & 0,21 & 8,33 & 0,43 & 0,01 & 0,05 & 0,69\end{array}$

$\begin{array}{llllllll}2 & 2 & 0,14 & 8,33 & 0,43 & 0,02 & 0,11 & 0,68\end{array}$

$\begin{array}{llllllll}3 & 3 & 0,21 & 8,33 & 0,43 & 0,01 & 0,03 & 0,67\end{array}$

$\begin{array}{llllllll}3 & 3 & 0,21 & 8,33 & 0,43 & 0,00 & 0,03 & 0,66\end{array}$

$\begin{array}{llllll}0,42 & 16,7 & 0,82 & 0,13 & 0,81 & 2,06\end{array}$

$\begin{array}{llllll}0,42 & 16,7 & 0,82 & 0,02 & 0,11 & 1,36\end{array}$

$\begin{array}{llllll}0,42 & 16,7 & 0,82 & 0,01 & 0,08 & 1,32\end{array}$

$\begin{array}{lllllll}0,42 & 16,7 & 0,82 & 0,05 & 0,34 & 1,58\end{array}$

$\begin{array}{llllll}0,21 & 16,7 & 0,82 & 0,01 & 0,07 & 1,1\end{array}$

$\begin{array}{llllll}0,21 & 16,7 & 0,82 & 0 & 0,02 & 1,06\end{array}$

$\begin{array}{lllllll}12,64 & 25 & 1,23 & 0,11 & 0,72 & 2,59\end{array}$

$\begin{array}{llllllll}46 & 2,44 & 66,7 & 3,29 & 0,82 & 5,21 & 10,9\end{array}$

$\begin{array}{lllllll}0,21 & 8,33 & 0,41 & 0 & 0,02 & 0,65\end{array}$

$\begin{array}{lllllll}10 & 0,53 & 25 & 1,23 & 0,06 & 0,37 & 2,14\end{array}$

$\begin{array}{llllll}0,21 & 16,7 & 0,82 & 0,01 & 0,09 & 1,12\end{array}$

$\begin{array}{llllll}0,21 & 8,33 & 0,41 & 0,01 & 0,03 & 0,66\end{array}$

$\begin{array}{llllll}- & - & - & - & - & -\end{array}$

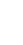

$\begin{array}{llllll}0,11 & 8,33 & 0,41 & 0,02 & 0,12 & 0,64\end{array}$

$\begin{array}{lllllll}4,13 & 66,7 & 3,29 & 0,21 & 1,33 & 8,75\end{array}$

$\begin{array}{lllllll}0,21 & 8,33 & 0,41 & 0,04 & 0,23 & 0,85\end{array}$

$\begin{array}{llllll}0,11 & 8,33 & 0,41 & 0,01 & 0,06 & 0,58\end{array}$

$\begin{array}{llllll}0,11 & 8,33 & 0,41 & 0,01 & 0,04 & 0,55\end{array}$

Revista Verde, v.13, n.4, p.508-520, 2018 
Euterpe edulis Mart.

Rapanea sp.

Handroanthus impetiginosus (Mart. ex DC.) Mattos

Eugenia acutata Miq.

Inga marginata Willd.

Indeterminada 18

Cecropia sp.

Indeterminada 19

Myrciaria glanduliflora (Kiaersk.)

Mattos \& D.Legrand

Randia ferox (Cham. \& Schltdl.)

DC.

Plenckia populnea Reissek

Machaerium stipitatum Vogel

Ouratea hexasperma (A.St.-Hil.)

Baill.

Myrsine gardneriana A.DC.

Indeterminada 20

Indeterminada 21

Indeterminada 22

Indeterminada 23

Siphoneugena crassifolia (DC.)

Proença \& Sobral

Indeterminada 24

Xylopia emarginata Mart.

Myrcia fenzliana O.Berg

Luehea paniculata Mart. \& Zucc.

Indeterminada 25

Allophylus edulis (A.St.-Hil. et al.)

Hieron. ex Niederl

Matayba elaeagnoides Radlk.

Miconia sp.

Luehea divaricata Mart. \& Zucc.

Aspidosperma ramiflorum

Müll.Arg.

Indeterminada 26

Indeterminada 27

Rhamnidium elaeocarpum Reissek

Indeterminada 28

Terminalia fagifolia Mart.

Indeterminada 29

Myrsine sp.

Sapium glandulosum (L.) Morong

Picranmia sp.

Handroanthus serratifolius (Vahl)

S.Grose

Indeterminada 30

Plathymenia reticulata Benth.

Indeterminada 31

Ixora brevifolia Benth.

Luehea sp.

Indeterminada 32

Psidium myrsinites DC.

Indeterminada 33

Indeterminada 34

Machaerium nyctitans (Vell.)

Benth.

Hymenolobium heringeranum

Rizzini

Styrax ferrugineus Nees \& Mart.

Inga sp.

Terminalia parviflora Thwaites $\begin{array}{llllllll}4 & 4 & 0,28 & 4,17 & 0,21 & 0,02 & 0,16 & 0,66\end{array}$

$\begin{array}{llllllll}5 & 5 & 0,35 & 4,17 & 0,21 & 0,01 & 0,08 & 0,64\end{array}$

$\begin{array}{llllllll}2 & 2 & 0,14 & 8,33 & 0,43 & 0,01 & 0,07 & 0,63\end{array}$

$\begin{array}{llllllll}2 & 2 & 0,14 & 8,33 & 0,43 & 0,01 & 0,06 & 0,63\end{array}$

$\begin{array}{llllllll}4 & 4 & 0,28 & 4,17 & 0,21 & 0,02 & 0,13 & 0,63\end{array}$

$\begin{array}{llllllll}5 & 5 & 0,35 & 4,17 & 0,21 & 0,01 & 0,06 & 0,63\end{array}$

$\begin{array}{lllllllll}1 & 1 & 0,07 & 4,17 & 0,21 & 0,05 & 0,34 & 0,62\end{array}$

$\begin{array}{llllllll}2 & 2 & 0,14 & 8,33 & 0,43 & 0,01 & 0,04 & 0,60\end{array}$

$\begin{array}{llllllllllllllll}2 & 2 & 0,14 & 8,33 & 0,43 & 0,00 & 0,03 & 0,60 & 2 & 4 & 0,21 & 16,7 & 0,82 & 0,02 & 0,13 & 1,16\end{array}$

$\begin{array}{llllllllllllllll}2 & 2 & 0,14 & 8,33 & 0,43 & 0,00 & 0,03 & 0,60 & 7 & 14 & 0,74 & 25 & 1,23 & 0,02 & 0,13 & 2,11\end{array}$

$\begin{array}{llllllll}2 & 2 & 0,14 & 8,33 & 0,43 & 0,00 & 0,03 & 0,60\end{array}$

$\begin{array}{llllllll}2 & 2 & 0,14 & 8,33 & 0,43 & 0,00 & 0,02 & 0,59\end{array}$

$\begin{array}{llllllll}2 & 2 & 0,14 & 8,33 & 0,43 & 0,00 & 0,01 & 0,58\end{array}$

$\begin{array}{llllllll}4 & 4 & 0,28 & 4,17 & 0,21 & 0,01 & 0,08 & 0,58\end{array}$

$\begin{array}{llllllll}3 & 3 & 0,21 & 4,17 & 0,21 & 0,01 & 0,10 & 0,52\end{array}$

$\begin{array}{llllllll}3 & 0,21 & 4,17 & 0,21 & 0,01 & 0,09 & 0,52\end{array}$

$\begin{array}{lllllll}2 & 0,14 & 4,17 & 0,21 & 0,02 & 0,16 & 0,51\end{array}$

$\begin{array}{llllllll}3 & 3 & 0,21 & 4,17 & 0,21 & 0,01 & 0,09 & 0,51\end{array}$

$\begin{array}{llllllll}3 & 3 & 0,21 & 4,17 & 0,21 & 0,01 & 0,08 & 0,50\end{array}$

$\begin{array}{llllllll}3 & 3 & 0,21 & 4,17 & 0,21 & 0,01 & 0,07 & 0,49\end{array}$

$\begin{array}{llllllll}2 & 2 & 0,14 & 4,17 & 0,21 & 0,02 & 0,14 & 0,49\end{array}$

$\begin{array}{llllllll}1 & 1 & 0,07 & 4,17 & 0,21 & 0,03 & 0,20 & 0,48\end{array}$

$\begin{array}{llllllll}3 & 3 & 0,21 & 4,17 & 0,21 & 0,01 & 0,05 & 0,47\end{array}$

$\begin{array}{llllllll}3 & 3 & 0,21 & 4,17 & 0,21 & 0,01 & 0,04 & 0,47\end{array}$

$3 \quad 3 \quad 0,21 \quad 4,17 \quad 0,21 \quad 0,01 \quad 0,04 \quad 0,46$

$\begin{array}{llllllll}1 & 1 & 0,07 & 4,17 & 0,21 & 0,03 & 0,18 & 0,46\end{array}$

$\begin{array}{llllllll}3 & 3 & 0,21 & 4,17 & 0,21 & 0,00 & 0,03 & 0,46\end{array}$

$\begin{array}{llllllll}2 & 2 & 0,14 & 4,17 & 0,21 & 0,01 & 0,10 & 0,45\end{array}$

$2 \quad 2 \quad 0,14 \quad 4,17 \quad 0,21 \quad 0,01 \quad 0,09 \quad 0,45$

$\begin{array}{llllllll}2 & 2 & 0,14 & 4,17 & 0,21 & 0,01 & 0,09 & 0,44\end{array}$

$\begin{array}{llllllll}1 & 1 & 0,07 & 4,17 & 0,21 & 0,02 & 0,15 & 0,43\end{array}$

$\begin{array}{llllllll}2 & 2 & 0,14 & 4,17 & 0,21 & 0,01 & 0,07 & 0,42\end{array}$

$\begin{array}{llllllll}2 & 2 & 0,14 & 4,17 & 0,21 & 0,01 & 0,06 & 0,42\end{array}$

$\begin{array}{llllllll}2 & 2 & 0,14 & 4,17 & 0,21 & 0,01 & 0,06 & 0,41\end{array}$

$\begin{array}{lllllllll}2 & 2 & 0,14 & 4,17 & 0,21 & 0,01 & 0,04 & 0,39\end{array}$

$\begin{array}{llllllll}2 & 2 & 0,14 & 4,17 & 0,21 & 0,00 & 0,03 & 0,38\end{array}$

$\begin{array}{llllllll}2 & 2 & 0,14 & 4,17 & 0,21 & 0,00 & 0,03 & 0,38\end{array}$

$\begin{array}{llllllll}2 & 2 & 0,14 & 4,17 & 0,21 & 0,00 & 0,03 & 0,38\end{array}$

$\begin{array}{llllllll}2 & 2 & 0,14 & 4,17 & 0,21 & 0,00 & 0,03 & 0,38\end{array}$

$\begin{array}{llllllll}2 & 2 & 0,14 & 4,17 & 0,21 & 0,00 & 0,03 & 0,38\end{array}$

$\begin{array}{llllllll}1 & 1 & 0,07 & 4,17 & 0,21 & 0,01 & 0,09 & 0,37\end{array}$

$\begin{array}{llllllll}2 & 2 & 0,14 & 4,17 & 0,21 & 0,00 & 0,02 & 0,37\end{array}$

$\begin{array}{lllllllll}2 & 2 & 0,14 & 4,17 & 0,21 & 0,00 & 0,01 & 0,37\end{array}$

$\begin{array}{llllllll}2 & 2 & 0,14 & 4,17 & 0,21 & 0,00 & 0,01 & 0,37\end{array}$

$\begin{array}{llllllll}2 & 2 & 0,14 & 4,17 & 0,21 & 0,00 & 0,01 & 0,37\end{array}$

$\begin{array}{llllllll}2 & 2 & 0,14 & 4,17 & 0,21 & 0,00 & 0,01 & 0,37\end{array}$

$\begin{array}{llllllll}2 & 2 & 0,14 & 4,17 & 0,21 & 0,00 & 0,01 & 0,37\end{array}$

$\begin{array}{llllllll}2 & 2 & 0,14 & 4,17 & 0,21 & 0,00 & 0,01 & 0,37\end{array}$

$\begin{array}{llllllll}1 & 1 & 0,07 & 4,17 & 0,21 & 0,01 & 0,07 & 0,35\end{array}$

$\begin{array}{llllllll}1 & 1 & 0,07 & 4,17 & 0,21 & 0,01 & 0,06 & 0,35\end{array}$

$\begin{array}{llllllll}6 & 12 & 0,64 & 33,3 & 1,65 & 0,19 & 1,18 & 3,46\end{array}$

$\begin{array}{llllll}0,07 & 4,17 & 0,21 & 0,01 & 0,05 & 0,33\end{array}$

$\begin{array}{lllllll}0,07 & 4,17 & 0,21 & 0,01 & 0,05 & 0,33\end{array}$

$\begin{array}{llllll}0,07 & 4,17 & 0,21 & 0,01 & 0,05 & 0,33\end{array}$ $\begin{array}{llllll}0,11 & 8,33 & 0,41 & 0 & 0,01 & 0,53\end{array}$

$\begin{array}{llllll}0,21 & 8,33 & 0,41 & 0,01 & 0,04 & 0,67\end{array}$

$\begin{array}{llllll}0,21 & 8,33 & 0,41 & 0,02 & 0,12 & 0,74\end{array}$

$\begin{array}{llllll}0,32 & 8,33 & 0,41 & 0,06 & 0,37 & 1,1\end{array}$ $\begin{array}{llllll}0,21 & 8,33 & 0,41 & 0,01 & 0,06 & 0,68\end{array}$ $\begin{array}{lllllll}0,21 & 16,7 & 0,82 & 0,04 & 0,24 & 1,27\end{array}$

$10 \quad 0,53 \quad 16,7 \quad 0,82 \quad 0,02 \quad 0,14 \quad 1,49$

$\begin{array}{lllllll}10 & 0,53 & 25 & 1,23 & 0,03 & 0,21 & 1,97\end{array}$

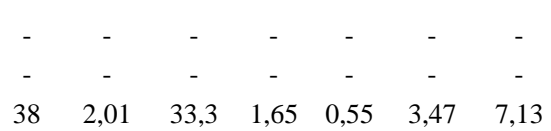

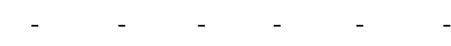


Machaerium opacum Vogel

Casearia grandiflora Cambess.

Drypetes sessiliflora Allemão

Erythrina verna Vell.

Byrsonima sp.

Callisthene major Mart.

Aspidosperma parvifolium A.DC.

Xylopia sp.

Centrolobium microchaete (Mart.

ex Benth.) H.C.Lima

Leptolobium elegans Vogel

Protium spruceanum (Benth.) Engl.

Lafoensia pacari A.St.-Hil.

Casearia sp.

Campomanesia guazumifolia

(Cambess.) O.Berg

Zanthoxylum sp.

Nectandra sp.

Eriotheca pubescens (Mart. \&

Zucc.) Schott \& Endl.

Sysygium sp.

Erythroxylum sp.

Schinus terebinthifolia Raddi

Handroanthus chrysotrichus (Mart. ex DC.) Mattos

Cassia sp.

Pilocarpus pennatifolius Lem.

Indeterminada 35

Indeterminada 36

Strychnos sp.

Lamanonia ternata Vell.

Monteverdia aquifolia (Mart.) Biral

Talisia esculenta (Cambess.) Radlk.

Helicteris sp.

Indeterminada 37

Garcinia gardneriana (Planch. \&

Triana) Zappi

Diptychandra aurantiaca Tul.

Machaerium brasiliense Vogel

Morus nigra L.

Nectandra nitidula Nees

Eugenia florida DC.

Indeterminada 38

Psidium rufum Mart. ex DC.

Tabernaemontana hystrix Steud.

Tocoyena formosa (Cham. \&

Schltdl.) K.Schum.

Machaerium sp.

Maytenus floribunda Reissek

Centrolobium sp.

Indeterminada 39

Trichilia pallida $\mathrm{Sw}$.

Plathyciamus sp.

Indeterminada 40

Indeterminada 41

Eugenia speciosa Cambess.

Psidium guajava $\mathrm{L}$

Diospyros lasiocalyx (Mart.)

B.Walln.

Swartzia multijuga Vogel

Virola sebifera Aubl.

Campomanesia eugenioides

(Cambess.) D.Legrand ex Landrum

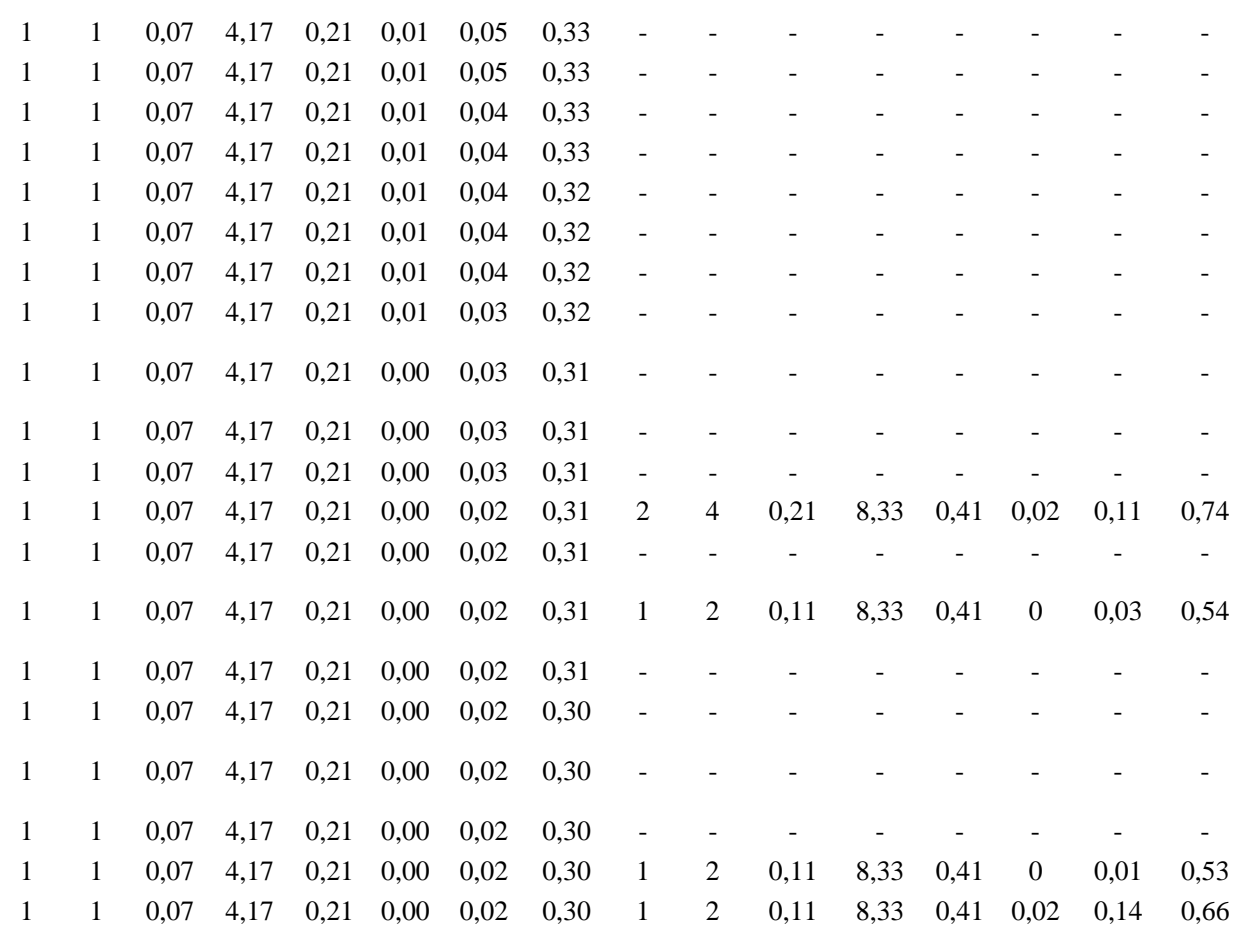

$\begin{array}{llllllll}1 & 1 & 0,07 & 4,17 & 0,21 & 0,00 & 0,01 & 0,30\end{array}$

$\begin{array}{llllll}0,07 & 4,17 & 0,21 & 0,00 & 0,01 & 0,30\end{array}$

$\begin{array}{lllllll}0,07 & 4,17 & 0,21 & 0,00 & 0,01 & 0,30\end{array}$

$\begin{array}{lllllll}0,07 & 4,17 & 0,21 & 0,00 & 0,01 & 0,30\end{array}$

$\begin{array}{lllllll}0,07 & 4,17 & 0,21 & 0,00 & 0,01 & 0,30\end{array}$

$\begin{array}{lllllll}0,07 & 4,17 & 0,21 & 0,00 & 0,01 & 0,30\end{array}$

$\begin{array}{lllllll}0,07 & 4,17 & 0,21 & 0,00 & 0,01 & 0,29\end{array}$

$\begin{array}{lllllll}0,07 & 4,17 & 0,21 & 0,00 & 0,01 & 0,29\end{array}$

$\begin{array}{lllllll}0,07 & 4,17 & 0,21 & 0,00 & 0,01 & 0,29\end{array}$

$\begin{array}{lllllll}0,07 & 4,17 & 0,21 & 0,00 & 0,01 & 0,29\end{array}$

$\begin{array}{llllll}0,07 & 4,17 & 0,21 & 0,00 & 0,01 & 0,29\end{array}$

$\begin{array}{llllll}0,07 & 4,17 & 0,21 & 0,00 & 0,01 & 0,29\end{array}$

$\begin{array}{llllll}0,07 & 4,17 & 0,21 & 0,00 & 0,01 & 0,29\end{array}$

$\begin{array}{lllllll}0,07 & 4,17 & 0,21 & 0,00 & 0,01 & 0,29\end{array}$

$\begin{array}{llllll}0,07 & 4,17 & 0,21 & 0,00 & 0,01 & 0,29\end{array}$

$\begin{array}{lllllll}0,07 & 4,17 & 0,21 & 0,00 & 0,01 & 0,29\end{array}$

$\begin{array}{lllllll}0,07 & 4,17 & 0,21 & 0,00 & 0,01 & 0,29\end{array}$

$\begin{array}{lllllll}0,07 & 4,17 & 0,21 & 0,00 & 0,01 & 0,29\end{array}$

$\begin{array}{lllllll}0,07 & 4,17 & 0,21 & 0,00 & 0,01 & 0,29\end{array}$

$\begin{array}{llllll}0,07 & 4,17 & 0,21 & 0,00 & 0,01 & 0,29\end{array}$

$\begin{array}{llllll}0,07 & 4,17 & 0,21 & 0,00 & 0,01 & 0,29\end{array}$

$\begin{array}{llllll}0,07 & 4,17 & 0,21 & 0,00 & 0,01 & 0,29\end{array}$

$\begin{array}{lllllll}0,07 & 4,17 & 0,21 & 0,00 & 0,01 & 0,29\end{array}$

$\begin{array}{lllllll}0,07 & 4,17 & 0,21 & 0,00 & 0,01 & 0,29\end{array}$

$\begin{array}{lllllll}0,07 & 4,17 & 0,21 & 0,00 & 0,01 & 0,29\end{array}$

$\begin{array}{lllllll}0,07 & 4,17 & 0,21 & 0,00 & 0,01 & 0,29\end{array}$

$\begin{array}{lllllll}0,07 & 4,17 & 0,21 & 0,00 & 0,01 & 0,29\end{array}$

$\begin{array}{lllllll}0,07 & 4,17 & 0,21 & 0,00 & 0,01 & 0,29\end{array}$

$\begin{array}{lllllll}0,07 & 4,17 & 0,21 & 0,00 & 0,00 & 0,29\end{array}$

$\begin{array}{llllll}0,07 & 4,17 & 0,21 & 0,00 & 0,00 & 0,29\end{array}$ $\begin{array}{llllll}0,11 & 8,33 & 0,41 & 0,02 & 0,14 & 0,66\end{array}$

$\begin{array}{llllll}0,32 & 8,33 & 0,41 & 0,03 & 0,17 & 0,9\end{array}$

$\begin{array}{llllll}0,11 & 8,33 & 0,41 & 0 & 0,03 & 0,54\end{array}$ 
Platypodium elegans Vogel

Terminalia januariensis DC.

Zollernia ilicifolia (Brongn.) Vogel

Erythroxylum deciduum A.St.-Hil.

Curatella americana $\mathrm{L}$.

Inga sessilis (Vell.) Mart.

Cupania vernalis Cambess.

Byrsonima laxiflora Griseb.

Heteropterys byrsonimifolia A.Juss.

Zanthoxylum riedelianum Engl.

Pseudobombax longiflorum (Mart.)

A.Robyns

Myrcia venulosa DC.

Indeterminada 42

Indeterminada 43

Indeterminada 44

Indeterminada 45

Indeterminada 46

Indeterminada 47

Indeterminada 48

Indeterminada 49

Indeterminada 50

Indeterminada 51

Indeterminada 52

Indeterminada 53

Indeterminada 54

Indeterminada 55

Indeterminada 56

Indeterminada 57

Agonandra brasiliensis Miers ex

Benth. \& Hook.f.

Tocoyena formosa (Cham. \&

Schltdl.) K.Schum.

Psidium ovale (Spreng.) Burret

Eugenia sonderiana O.Berg

Miconia albicans (Sw.) Triana

\begin{tabular}{cccccccc}
1 & 2 & 0,11 & 8,33 & 0,41 & 0,07 & 0,42 & 0,93 \\
2 & 4 & 0,21 & 8,33 & 0,41 & 0,04 & 0,25 & 0,88 \\
3 & 6 & 0,32 & 8,33 & 0,41 & 0,01 & 0,06 & 0,79 \\
3 & 6 & 0,32 & 16,7 & 0,82 & 0,01 & 0,06 & 1,2 \\
1 & 2 & 0,11 & 8,33 & 0,41 & 0,01 & 0,08 & 0,59 \\
1 & 2 & 0,11 & 8,33 & 0,41 & 0,01 & 0,05 & 0,57 \\
10 & 20 & 1,06 & 8,33 & 0,41 & 0,15 & 0,93 & 2,4 \\
14 & 28 & 1,48 & 33,3 & 1,65 & 0,06 & 0,39 & 3,52 \\
7 & 14 & 0,74 & 16,7 & 0,82 & 0,04 & 0,26 & 1,82 \\
3 & 6 & 0,32 & 16,7 & 0,82 & 0,08 & 0,53 & 1,67 \\
2 & 4 & 0,21 & 8,33 & 0,41 & 0,1 & 0,62 & 1,24 \\
5 & 10 & 0,53 & 16,7 & 0,82 & 0,02 & 0,13 & 1,49 \\
1 & 2 & 0,11 & 8,33 & 0,41 & 0 & 0,03 & 0,54 \\
1 & 2 & 0,11 & 8,33 & 0,41 & 0 & 0,03 & 0,55 \\
1 & 2 & 0,11 & 8,33 & 0,41 & 0,03 & 0,21 & 0,72 \\
9 & 18 & 0,95 & 16,7 & 0,82 & 0,09 & 0,59 & 2,36 \\
3 & 6 & 0,32 & 16,7 & 0,82 & 0,06 & 0,39 & 1,53 \\
2 & 4 & 0,21 & 16,7 & 0,82 & 0,01 & 0,06 & 1,09 \\
3 & 6 & 0,32 & 25 & 1,23 & 0,09 & 0,57 & 2,12 \\
5 & 10 & 0,53 & 16,7 & 0,82 & 0,01 & 0,09 & 1,44 \\
11 & 22 & 1,17 & 8,33 & 0,41 & 0,09 & 0,59 & 2,16 \\
1 & 2 & 0,11 & 8,33 & 0,41 & 0 & 0,02 & 0,54 \\
22 & 44 & 2,33 & 50 & 2,47 & 0,39 & 2,5 & 7,3 \\
1 & 2 & 0,11 & 8,33 & 0,41 & 0 & 0,02 & 0,54 \\
5 & 10 & 0,53 & 8,33 & 0,41 & 0,22 & 1,37 & 2,32 \\
2 & 4 & 0,21 & 8,33 & 0,41 & 0,01 & 0,06 & 0,68 \\
1 & 2 & 0,11 & 8,33 & 0,41 & 0,01 & 0,07 & 0,59 \\
1 & 2 & 0,11 & 8,33 & 0,41 & 0,03 & 0,19 & 0,71 \\
2 & 4 & 0,21 & 8,33 & 0,41 & 0,02 & 0,12 & 0,74 \\
& & & & & & & \\
2 & 4 & 0,21 & 16,7 & 0,82 & 0,01 & 0,04 & 1,07 \\
1 & 2 & 0,11 & 8,33 & 0,41 & 0,02 & 0,11 & 0,63 \\
1 & 2 & 0,11 & 8,33 & 0,41 & 0 & 0,02 & 0,54 \\
1 & 2 & 0,11 & 8,33 & 0,41 & 0 & 0,01 & 0,53 \\
\hline
\end{tabular}

O diâmetro dos indivíduos exibiu um intervalo de 3,03 a $77,07 \mathrm{~cm}$ para o interior, sendo que a espécie Cariniana estrellensis (Raddi) Kuntze, foi a de maior diâmetro, e 3,02 a $75,80 \mathrm{~cm}$ para a zona de amortecimento, em que a espécie Enterolobium gummiferum (Mart.) J. F. Macbr. apresentou maior diâmetro. Além disso, as áreas apresentaram uma distribuição diamétrica com mais de $70 \%$ dos indivíduos concentrados na primeira classe e com poucos nas classes seguintes. Ainda assim, as áreas possuem um comportamento de J-invertido, o padrão de distribuição de diâmetro esperado para as florestas naturais. $\mathrm{O}$ acúmulo de indivíduos nas primeiras classes indica uma comunidade que possui potencial de manter sua estrutura ao longo do tempo, com um bom estoque de indivíduos jovens e em percurso para que estes alcancem estágios mais avançados na comunidade (CARVALHO; NASCIMENTO, 2009) (Figura 1).

Além disso, a região do estudo possui condições edafoclimáticas desfavoráveis para grandes incrementos em diâmetro, o que pode estar influenciando no atual panorama da vegetação. Assim também um estudo realizado sobre a caracterização estrutural do Barbatimão em vegetação semelhante na região argumenta sobre essa possibilidade, para confirmar o baixo número de indivíduos nas classes de maiores diâmetros (MEIRA et al., 2016).
Figura 1. Estrutura diamétrica do interior e zona de amortecimento da unidade de conservação no Parque Estadual Lapa Grande, no município de Montes Claros, Minas Gerais.

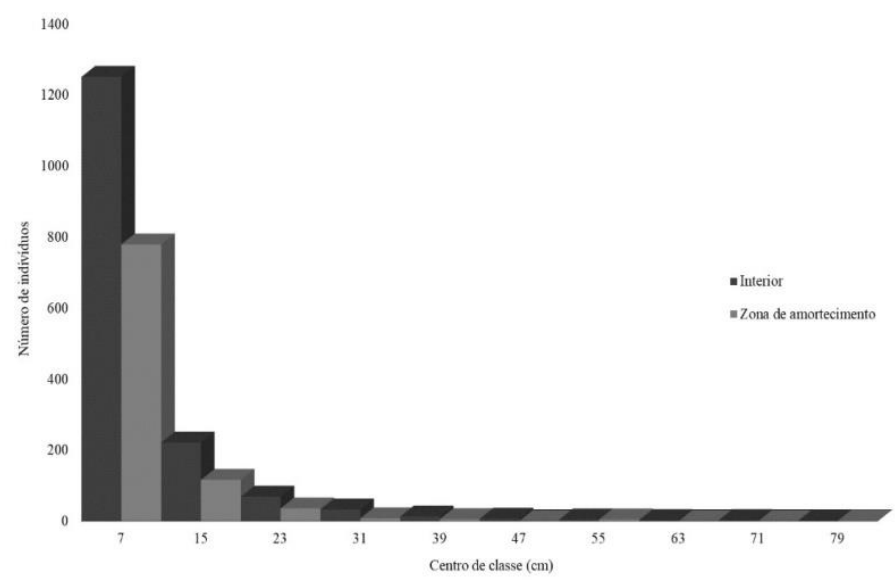

Em relação à altura dos indivíduos, a área do interior variou de 1,70 a $35 \mathrm{~m}$ e a zona de amortecimento de 1,4 a 16,4 m. A vegetação apresentou uma maior concentração de indivíduos no estrato médio tanto para a área de interior quanto para a zona de amortecimento, com mais de $78 \%$ de indivíduos do total amostrado nesta classe. 
Concomitantemente com a estrutura diamétrica, a hipsométrica permite inferir sobre o estágio de desenvolvimento da vegetação, visto que, por meio dessas análises obtém-se informações referente à distribuição dos indivíduos na área (MARANGON et al., 2008). Os resultados mostram que a floresta possui uma grande quantidade de indivíduos no estrato médio indicando que a vegetação pode estar alcançando novos estágios na sucessão. (FIGURA 2).

Figura 2. Estrutura hipsométrica considerando o número de indivíduos por classe de altura para o interior e zona de amortecimento da unidade de conservação no Parque Estadual Lapa Grande, no município de Montes Claros, Minas Gerais

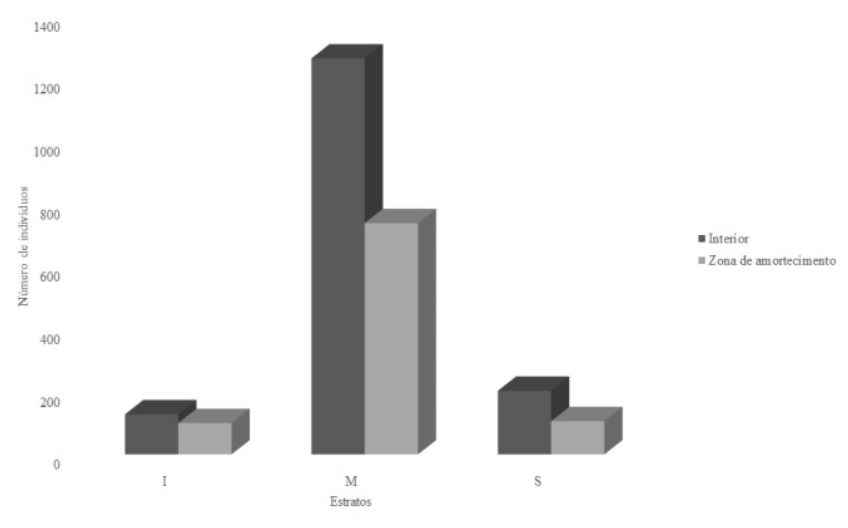

$\mathrm{O}$ índice de diversidade de Shannon (H') encontrado para o interior da unidade de conservação foi de 4,61 nats. ind $^{-1}$, a equabilidade de Pielou de 0,85 e a área basal de 15,37 $\mathrm{m}^{2} \mathrm{ha}^{-1}$. Em relação a sua zona de amortecimento, os valores de diversidade foram de 3,79 nats. ind $^{-1}$, equabilidade de 0,82 e área basal de $16,35 \mathrm{~m}^{2} \mathrm{ha}^{-1}$. Quando comparado com estudos realizados em áreas similares, os valores de diversidade estão no intervalo encontrado de 3,27 a 4,64 nats. ind $^{-1}$ e equabilidade de 0,76 a 0,98 (BAMBI et al., 2016; CARVALHO et al., 2005; MINAMI et al., 2017). Para o valor de equabilidade de Pielou, observou-se uma uniformidade dos indivíduos, tanto para o interior quanto para a zona de amortecimento, pois apresentam um índice maior que 0,8 , sendo este, um valor intermediário para o intervalo encontrado. Além disso, constatou-se um valor de diversidade mais alto para o interior, quando comparado a área da zona de amortecimento. Dessa forma, ao realizar a análise estatística dos valores de diversidade com o teste $t$ de Hutcheson foi observado uma diferença significativa entre as diversidades das duas áreas, com valores de t igual a 10,98 para $\mathrm{p}<0,001$. Por meio desses resultados é possível verificar uma simplificação da comunidade arbórea da zona de amortecimento, com um declínio da diversidade, principalmente, pela pertinência da área em suportar um maior impacto e servir como um filtro ambiental para unidade de conservação (COSTA et al., 2013) (Tabela 2). Além disso, este resultado mostra a importância da unidade de conservação para manutenção das espécies da Mata Ripária.

Tabela 2. Comparação dos parâmetros de diversidade de Shannon e Equabilidade de Pielou para diferentes áreas de mata ripária no Domínio Cerrado. Em que: $\mathrm{H}^{\prime}$ = índice de Shannon-Wiener; J' = equabilidade de Pielou; ZA: Zona de amortecimento.

\begin{tabular}{ccccc}
\hline Local & Fitofisionomia & H' & J & Citação \\
& & & & \\
Presente estudo & Mata Ripária - Interior & 4,61 & 0,85 & \\
Presente estudo & Mata Ripária - ZA & 3,79 & 0,82 & (BAMBI et al., 2016) \\
Jardim Botânico de Brasília- DF & Mata de galeria & 4,64 & 0,98 & (MINAMI et al., 2017) \\
Nova Mutum-MT & Mata de galeria & 3,27 & 0,94 & (MIN \\
Três Marias-MG & Mata Ripária & 3,73 & 0,76 & (CARVALHO et al., 2005) \\
\hline
\end{tabular}

Ao realizar a similaridade das parcelas das duas áreas, utilizando o método de agrupamento, é perceptível a formação de grupos fracamente ligados, e consequentemente uma dissimilaridade destas, apesar da sua proximidade territorial. Essas diferenças foram observadas tanto em comparações quantitativas quanto em quesitos qualitativos. Ademais, foram formados grupos entre as duas áreas de estudo e também entre as parcelas dentro de cada área, indicando que existe uma heterogeneidade da composição florística e estrutural dos dados amostrados. As dessemelhanças nas áreas são normalmente encontradas em áreas de Matas Ripárias tanto em dimensão geográfica quanto em escala local, pois essa vegetação é caracterizada por uma alta riqueza florística e por diferentes microambientes (RIBEIRO-FILHO et al., 2009; SILVA et al., 2017) (Figura 3A e Figura 3B).
Por meio da análise de correspondência distendida foi possível verificar a existência de um longo gradiente, com alta substituição florística entre as comunidades, pois os valores dos eixos foram significativos, considerando um valor padrão maior que 0,3 para florestas heterogêneas (FELFILI et al., 2011). Os autovalores foram de 0,78 para o eixo 1 e 0,56 para o eixo 2. Assim também, encontramos a diferenciação das parcelas da zona de amortecimento com as parcelas de interior, com clara formação de grupos dessas duas áreas, sendo que as parcelas que estão no interior da unidade de conservação apresentam uma maior distribuição dos dados no diagrama. Esses resultados corroboram com dados de similaridade das parcelas, que comprovam a diferenciação dos atributos da vegetação para a área protegida e sua zona de amortecimento, mesmo em pequenas escalas (Figura 4). 
Figura 3. Dendrograma de similaridade das parcelas comparando a área de Mata Ripária Interior com a área da zona de amortecimento. Quadrados cheios são referentes à Mata Ripária Interior e quadrados vazios referentes à zona de amortecimento. 3A) coeficiente quantitativo de Morisita-Horn; correlação cofenética =0,77 e 3B) coeficiente qualitativo de Jaccard; correlação cofenética $=0,79$.
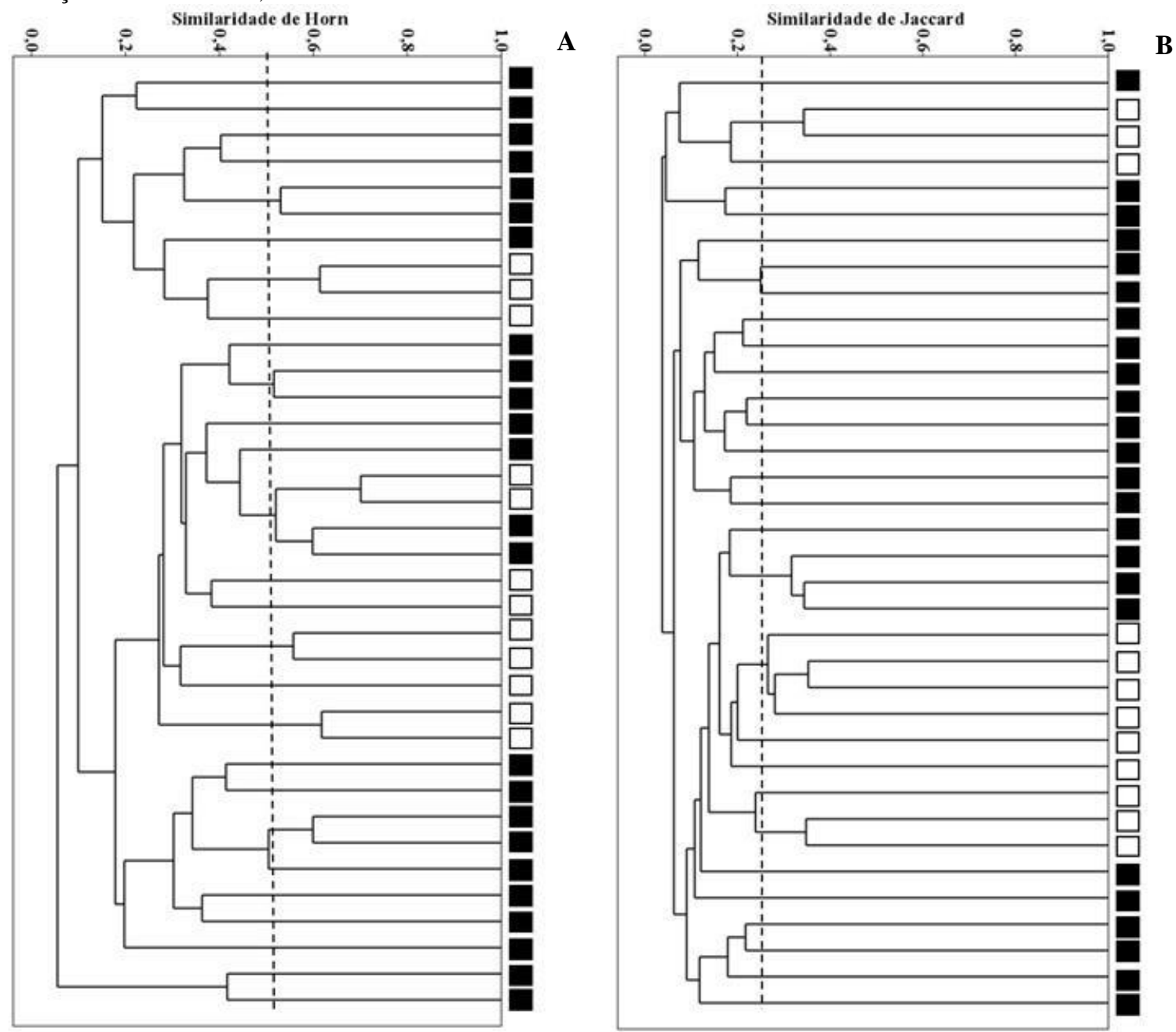

Figura 4. Diagrama de ordenação resultante da análise de correspondência distendida (DCA) mostrando disposição das parcelas das áreas do interior da zona de amortecimento em relação à composição quantitativa (densidade absoluta) de espécies amostradas da Mata Ripária no Parque Estadual da Lapa Grande, Minas Gerais. Símbolo cinza são referentes à Mata Ripária Interior e símbolo preto referentes à zona de amortecimento. Autovalores: Eixo 1 = 0,78; Eixo $2=0,56$.

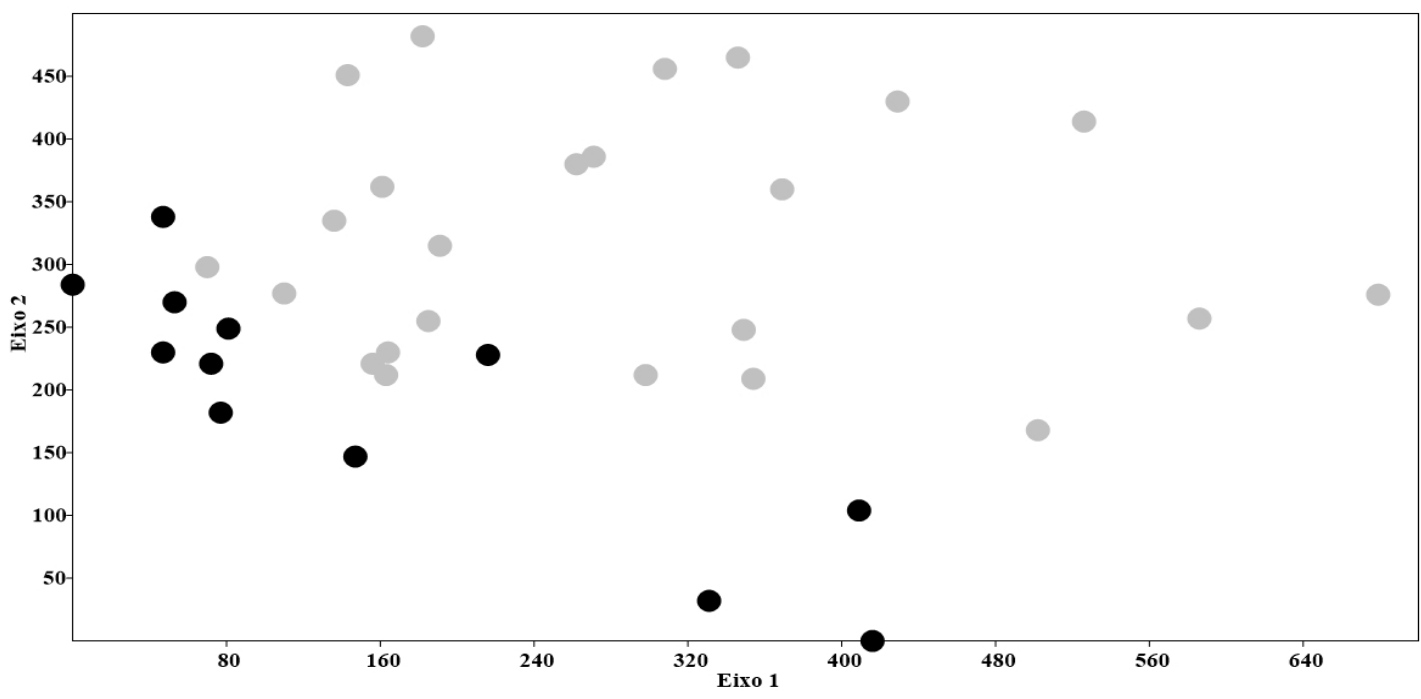




\section{CONCLUSÕES}

A Mata Ripária do interior do Parque Estadual da Lapa Grande na região de Montes Claros, Minas Gerais, apresenta uma expressiva riqueza e diversidade quando comparada à sua área da zona de amortecimento. Essa elevada riqueza provoca uma baixa dominância ecológica e alta heterogeneidade, o que pode estar relacionado à estrutura da vegetação. No entanto, é notável a relevância existente da zona de amortecimento para a conservação, visto que, tem propiciado uma contenção dos impactos antrópicos para o interior da unidade de conservação, sendo um fator de influência direta na composição e diversidade das espécies. Nesse contexto, as áreas da unidade de conservação e sua zona de amortecimento desempenham um papel de importância para biodiversidade, uma vez que, prestam serviços ambientais imprescindíveis para a conservação de espécies e manutenção da água nos mananciais.

\section{AGRADECIMENTOS}

Os autores agradecem à Universidade Federal de Minas (UFMG), Instituto de Ciências Agrárias (ICA), Instituto de Florestas (IEF), Parque Estadual da Lapa Grande (PELG) e a Universidade Federal de Lavras (UFLA) pela estrutura necessária para o desenvolvimento do estudo, bem como à Coordenaria de Aperfeiçoamento de Pessoal de Nível Superior (CAPES) pela concessão da bolsa. Por fim, agradecemos à Janaína D. do Prado pela revisão ortográfica no manuscrito.

\section{REFERÊNCIAS}

ALVARES, C. A.; STAPE, J. L.; SENTELHAS, P. C.; GONÇALVES, J. L. de M.; SPAROVEK, G. Köppen's climate classification map for Brazil. Meteorologische Zeitschrift, v. 22, n. 6, p. 711-728, 2013. 10.1127/09412948/2013/0507.

APG, Angiosperm Phylogeny Group. An update of the Angiosperm Phylogeny Group classification for the orders and families of flowering plants: APG IV. Botanical Journal of the Linnean Society, v. 181, p. 1-20, 2016. 10.1111/boj.12385.

BAMBI, P.; REZENDE, R. S.; CRUZ, T. M. S.; BATISTA, J. E. de A.; MIRANDA, F. G. G. F.; SANTOS, L. V. dos; GONÇALVES JÚNIOR, J. F. Diversidade da flora fanerogâmica de três matas de galeria no bioma cerrado. Heringeriana, v. 10, n. 2, p. 147-167, 2016. 10(2): 147-167. 2016.

BRANCALION, P. H. S.; GARCIA, L. C.; LOYOLA, R.; RODRIGUES, R. R.; PILLAR, V. D.; LEWINSOHN, T. M. Análise crítica da Lei de Proteção da Vegetação Nativa (2012), que substituiu o antigo Código Florestal: atualizações e ações em curso. Natureza \& Conservação, v. 14, n. abril, p. e1-e16, 2016. 10.1016/j.ncon.2016.03.004.

BROWER, J. E.; ZAR, J. H. von ENDE, C. N. Field and laboratory methods for general ecology. 4 ed. New York: WCB McGraw-Hill, 1997. 273p.
CARVALHO, D. A.; OLIVEIRA FILHO, A. T.; VILELA, E. A.; CURI, N.; VAN DEN BERG, E.; FONTES, M. A. L. BOTEZELLI, L. Distribuição de espécies arbóreo-arbustivas ao longo de um gradiente de solos e topografia em um trecho de floresta ripária do rio São Francisco em Três Marias, MG, Brasil. Revista Brasileira de Botânica, v. 28, n. 2, p. 329-345, 2005. 10.1590/S0100-84042005000200013.

CARVALHO, F. A.; NASCIMENTO, M. T. Estrutura diamétrica da comunidade e das principais populações árboreas de um remanescente de Floresta Atlântica Submontana. Árvore, v. 33, n. 2, p. 327-337, 2009. 10.1590/S0100-67622009000200014.

CASTRO, M. N.; CASTRO, R. M.; SOUZA, P. C. DE. A importância da mata ciliar no contexto da conservação do solo. Revista Eletrônica de educação da Faculdade Araguaia, v. 4, n. 4, p. 230-241, 2013.

CERQUEIRA, C. L.; LISBOA, G. S.; STEPKA, T. F.; LOPES, M. S.; VENDRUSCOLO, D. G. S.; FRANÇA, L. C. de J.; MIRANDA, D. L. C. Floristic, Phytosociology and Diametric Distribution of a Fragment of Ciliary Area in a Cerrado Area in Piauí, Brazil. Nativa, v. 4, n. 6, p. 360-367, 2016. 10.14583/2318-7670.v04n06a03.

CHAVES, T. F. Uma Análise dos principais impactos ambientais verificados no Estado de Santa Catarina. Revista Gestão \& Sustentabilidade Ambiental, v. 5, n. 2, p. 611-634, 2016. 10.19177/rgsa.v5e22016611-634.

COSTA, D. R. T. R.; BOTEZELli, L.; SILVA, B. G.; FARIAS, O. L. M.. Zonas de Amortecimento em Unidades de Conservação: levantamento legal e comparativo das normas nos Estados de Minas Gerais, Rio de Janeiro e São Paulo. Desenvolvimento e Meio ambiente, v. 27, n. jan/jun, p. 5770, 2013. 10.5380/dma.v27i0.28036.

FELFILI, J. M.; CARVALHO, F. A.; VENTUROLI, F.; PEREIRA, B. A. S.; LÍBANO, A. M.; MACHADO, E. L. M. Análise multivariada: princípios e métodos em estudos de vegetação. In: FELFILI, J. M.; EISENLOHR, P. V.; MELO, M. M. R. F.; ANDRADE, L. A.; MEIRA NETO, J. A. A. (eds.). Fitossociologia no Brasil: métodos e estudos de caso. Viçosa: Editora UFV, 2011. cap. 4, p. 122-155.

FINGER, Z.; FINGER, F. A. Fitossociologia em comunidades arbóreas remanescentes de Cerrado sensu stricto no Brasil Central. Revista Floresta, v. 45, n. 4, p. 769-780, 2015. 10.5380/rf.v45i4.30860.

Flora do Brasil 2020 em construção. Jardim Botânico do Rio de Janeiro. Disponível em: < http://floradobrasil.jbrj.gov.br/ >. Acesso em: 02 Mai. 2018.

FLORES, A. S.; RODRIGUES, R. S. Diversidade de Leguminosae em uma área de savana do estado de Roraima, Brasil. Acta Botanica Brasilica, v. 24, n. 1, p. 175-183, 2010. 10.1590/S0102-33062010000100017.

GARÇÃO, L. M. DA C.; SOUZA, D. G. Caracterização da fitofisionomia do cerrado no município de Porangatu. Revista Mirante, v. 10, n. 2, p. 158-172, 2017. 
HAMMER, Ø.; HARPER, D. A. T.; RYAN, P. D. Paleontological statistics software package for education and data analysis. Palaeontologia Electronica, v. 4, n. 1, p. 9-18, 2001.

KUNZ, S. H.; MOREAU, J.; SPADETO, C.; MARTINS, S. V.; STEFANELLO, D.; IVANAUSKAS, N. M. Estrutura da comunidade arbórea de trecho de Floresta Estacional SempreVerde e similaridade florística da região nordeste do Mato Grosso, Brasil. Floram, v. 21, n. 4, p. 429-440, 2014 10.1590/2179-8087.029313.

MALCZEWSKI, F. L.; FRITSCH, M.; POVALUK, M. Ocorrência de Fabaceae - Mimosoidea em apps da faixa de domínio da rodovia BR-116, trecho Curitiba, PR a Capão Alto, SC. Saúde e Meio Ambiente, v. 3, n. 2, p. 102-117, 2014. 10.24302/sma.v3i2.549.

MARANGON, L. C.; FELICIANO, A. L. P.; BRANDÃO, C. F. L. S.; ALVES JÚNIOR, F. T. A. Relações florísticas, estrutura diamétrica e hipsométrica de um fragmento de Floresta Estacional Semidecidual em Viçosa (MG). Floresta v. 38, n. 4, p. 699-709, 2008. 10.5380/rf.v38i4.13166.

MEIRA, M. R.; CABACINHA, C. D.; GAMA, A. T.; MARTINS, E. R.; FIGUEIREDO, L. S de. Caracterização estrutural do Barbatimão (Stryphnodendron adstringens (Mart.) Coville) no Cerrado do Norte de Minas Gerais. Ciência Florestal, v. 26, n. 2, p. 627-638, 2016. $10.5902 / 1980509822762$.

MINAMI, P.; RIBEIRO, E. S.; MARTINS, V. G.; MOREIRA, E. L. Florística e Fitossociologia em Mata de Galeria e Cerradão no município de Nova Mutum - MT, Brasil. Biodiversidade, v. 16, n. 1, p. 46-63, 2017.

MINAS GERAIS. Decreto $\mathrm{n}^{\circ} 44.204$, de 10 de janeiro de 2006. Cria o Parque Estadual da Lapa Grande, no Município de Montes Claros. Diário do Executivo; Minas Gerais, 2006.

MORENO, C.; MAGALHÃES, F. C.; REZENDE, L. H. G.; NEVES, K.; FERRO, V. Riqueza e composição de Arctiinae (Lepidoptera, Eribidae) em cinco Unidades de Conservação do Cerrado. Ilheringia, v. 105, n. 3, p. 297-306, 2015. 10.1590/1678-476620151053297306.

MORETTO, S. P. Na fronteira do cerrado: as transformações ambientais no norte de Goiás. Revista Expedições: Teoria da História e Historiografia, v. 7, n. 1, p. 119-130, 2016.

MORO, M. F.; MARTINS, F. R. Métodos de Levantamento do Componente Arbóreo-Arbustivo. In: FELFILI, J. M.; EISENLOHR., P. V.; MELO, M. M. da R. F de.; ANDRADE, L. A. de.; MEIRA NETO, J. A. A. (Eds.) Fitossociologia no Brasil: métodos e estudos de caso. Viçosa: Editora UFV, 2011. p. 558.

MUELLER-DOMBOIS, D.; ELLENBERG, H. Aims and Methods of Vegetation Ecology. 1 ed. New York: John Wiley \& Sons, 1974
NASCIMENTO, C. M. D.; DOMINGUEZ， L. M. J Remanescentes da cobertura vegetal: uma contribuição cartográfica à gestão ambiental no zona costeira dos municípios de Belmonte e Canavieiras na Bahia. Caderno de Geociências, v. 7, n. 2, p. 93-104, 2010.

NORA, E. L. D.; SANTOS, J. E. dos. Dinâmica ambiental da zona de amortecimento de áreas naturais. Revista Ambiência, v. 7, n. 2, p. 279-293, 2011. 10.5777/ambiencia.2011.02.06.

NUNES, Y. R. F, AZEVEDO, I. F. P.; NEVES, W. V.; VELOSO, M. das D. M.; SOUZA, R. de A.; G. FERNANDES, G. W. Pandeiros: o Pantanal Mineiro. MG.Biota, v. 2, n. 2, p. 4-17, 2009.

OLIVEIRA, L. C. de; PEREIRA, R.; VIEIRA, J. R. G. Análise da degradação ambiental da mata ciliar em um trecho do Rio Maxaranguape_RN: uma contribuição à gestão dos recursos hídricos do Rio Grande do Norte - Brasil. Holos, v. 5, p. 49-66, 2011. 10.15628/holos.2011.595.

OLIVEIRA, L. C. da S.; GUIMARÃES, J. C. O.; SOUZA, I. C. S.; LIMA, C. M. F.; WENDY C. Levantamento florístico e fitossociológico da regeneração natural de uma mata de galeria localizada no município de Jataí - GO. Global Science and Technology, v. 8, p. 59-77, 2015. 10.14688/19843801/gst.v8n3p59-77.

PEREIRA, K. G. Mirtáceas da formação entre-córregos, paleógeno da bacia de Aiuruoca, estado de Minas Gerais, Brasil: sua taxonomia e interpretações paleoclimáticas, paleofitogeográficas e paleoecológicas. 2015. 139p. Dissertação (Mestrado em Análise Geoambiental) Universidade de Guarulhos, Guarulhos. 2015.

RIBEIRO, J. F.; WALTER, B. M. T. Fitofisionomias do bioma Cerrado. In: SANO, S. M.; ALMEIDA, S. P. de (Ed.). Cerrado: ambiente e flora. Planaltina: EMBRAPA-CPAC, 1998. p. 89-166.

RIBEIRO-FILHO, A. A.; FUNCH, L. S.; RODAL, M. J. N. Composição florística da floresta ciliar do rio Mandassaia, Parque Nacional da Chapada Diamantina, Bahia, Brasil. Rodriguésia, v. 60, n. 2, p. 265-276, 2009. 10.1590/21757860200960203.

SALAMENE, S.; FRANCELINO, M. R.; VALCARCEL, R.; LANI, J. L.; SÁ, M. M. F. Estratificação e caracterização ambiental da área de preservação permanente do Rio Guandu/ RJ. Revista Árvore, v. 35, n. 2, p. 221-231, 2011. 10.1590/S0100-67622011000200007.

SANO, E. E.; ROSA, R.; BRITO, J. L. S.; FERREIRA, L. G. Land cover mapping of the tropical savanna region in Brazil. Environmental monitoring and assessment, v. 166, n. 1-4, p. 113-24, 2010. 10.1007/s10661-009-0988-4.

SILVA NETO, V. L.; OLIVEIRA, A. L de.; FERREIRA, R. Q. de S.; SOUZA, P. B. de; VIOLA, M. R. Fitossociologia e distribuição diamétrica de uma área de Cerrado sensu stricto, Dueré-TO. Revista de Ciências Ambientais, v. 10, n. 1, p. 91106, 2016. 10.18316/1981-8858.16.24. 
SILVA, M. R.; LACERDA, D. B. C. L.; SANTOS, G. G.; MARTINS, D. M. de O. Caracterização química de frutos nativos do cerrado. Ciência Rural, v. 38, n. 6, p. 1790-1793, 2008. 10.1590/S0103-84782008000600051.

SILVA, S. B.; SOUSA, V. C.; SANTOS, C. M.; MARIANO, D. C; OKUMURA, R. S. Levantamento florístico do componente arbustivo-arbóreo da vegetação ciliar de fragmento no Rio Parauapebas. Agroecossistemas, v. 9, n. 1, p. 99-115, 2017. 10.18542/ragros.v9i1.4780.

SILVA-JÚNIOR, C. M.; PEREIRA, B. A. 100 árvores do Cerrado - Matas de Galeria. 1. ed. Brasília - DF: Rede de Sementes do Cerrado, 2012.

SIMON, M. F.; GRETHER, R.; QUEIROZ, L. P. de; SKEMA, C.; PENNINGTON, R. T.; HUGHES, C. E. Recent assembly of the Cerrado, a neotropical plant diversity hotspot, by in situ evolution of adaptations to fire. PNAS, v. 106, n 48, p. 20359-20364, 2009. 10.1073/pnas.0903410106.

SOUZA, L. A. G. DE. Levantamento da habilidade nodulífera e fixação simbiótica de N2 nas Fabaceae da Região Amazônica. Enciclopédia Biosfera, v. 6, n. 10, p. 1-11, 2010.

STRASSBURG, B. B. N.; BROOKS, T.; FELTRANBARBIERI, R.; IRIBARREM, A.; CROUZEILLES, R.; LOYOLA, R.; LATAWLEC, A. E.; OLIVEIRA FILHO, F. J. B.; SCARAMUZZA, C. A. de M.; SCARANO, F. R.; SOARES-FILHO, B.; BALMFORD, A. Moment of truth for the Cerrado hotspot. Nature Ecology \& Evolution, v. 1, n. 0099, p. 1-3, 2017. 10.1038/s41559-017-0099.

TILMAN, D.; CLARK, M.; WILLIAMS, D. R.; KIMMEL, K.; POLASKY, S.; PACKER, C. Future threats to biodiversity and pathways to their prevention. Nature, v. 546, n. June, p. 73-81 2017. 10.1038/nature22900.

TOLLEFSON, J. Deforestation ticks up in Brazil's savannah. Nature. Published online, 12 July 2018. doi:10.1038/d41586018-05695-9. 